\title{
Construction Theory and Noise Analysis Method of Global CGCS2000 Coordinate Frame
}

\author{
JIANG Zhihao ${ }^{1,2}$, Wang Fan², BAI Ju² , Li Zongquan ${ }^{2}$ \\ ${ }^{1}$ School of Geodesy and Geomatics, Wuhan University, Wuhan 430079, China - zhjiang@ngcc.cn \\ ${ }^{2}$ National Geomatics Center of china, Beijing 100830, China
}

KEY WORDS: CGCS2000 globalization, coordinate time series Noise analysis, construction of geocentric reference frame, Geodetic datum

\begin{abstract}
:
The definition, renewal and maintenance of geodetic datum has been international hot issue. In recent years, many countries have been studying and implementing modernization and renewal of local geodetic reference coordinate frame. Based on the precise result of continuous observation for recent 15 years from state CORS (continuously operating reference system) network and the mainland GNSS (Global Navigation Satellite System) network between 1999 and 2007, this paper studies the construction of mathematical model of the Global CGCS2000 frame, mainly analyzes the theory and algorithm of two-step method for Global CGCS2000 Coordinate Frame formulation. Finally, the noise characteristic of the coordinate time series are estimated quantitatively with the criterion of maximum likelihood estimation.
\end{abstract}

\section{INTRODUCTION}

CGCS2000 (China Geodetic Coordinate System 2000) has been adopted nearly 10 years since July 1, 2008 (Yang, 2009), which was composed of CORS network and national high-precision geodetic control network. In recent years, with relevant state construction project successfully implemented, the number of China's national CORS stations has reached 410, and evenly covered China's territorial lands, becoming the mainstay of maintaining the CGCS2000 coordinate framework (Liu, 2009). Based on the processing results of the 16-year national CORS station, this paper studies the theory and algorithm of constructing the global CGCS2000 coordinate reference frame using the two-step model, and the noise characteristic of the coordinate time series are estimated quantitatively with the criterion of maximum likelihood estimation.

\section{DATA PROCESSING AND VELOCITY ESTIMATING}

The software named GAMIT/GLOBK had been used in data processing and adjustment for CORS sites. GAMIT is a comprehensive GPS analysis package developed at MIT and Scripps for the estimation of three-dimensional relative positions of ground stations and satellite orbits base on the GPS double-difference. GLOBK is a Kalman filter whose primary purpose is to combine solutions from the processing of primary data from space-geodetic or terrestrial observations.

Two steps are adopted to obtain the coordinates and velocities information of CORS. First, performing a least squares analysis, which is completed by GAMIT software. Second, according to CORS time series, we carry on adjustment after daily CORS solution, and estimate velocity adopting Kalman filter method, completed by GLOBK software (Jiang, 2009). The map of national CORS stations are represented in Figure 1.

In order to strengthen the geometry relation between Domestic CORS sites and global IGS (International GNSS Service) stations, in the daily GPS processing, we add surrounding 16 IGS stations, so we can obtained the agonic solution of position and covariance and improve the intensity of entire CORS network (Jiang, 2009). After joint processing and adjustment for CORS and IGS GPS stations, we can obtain the velocities and coordinates in model of global crust movements. Finally, the coordinates and velocities all had been transferred to CGCS2000 frames (Jiang, 2012). The velocity of national CORS stations (CGCS2000) are represented in Figure 2.

\section{CONSTRUCTION OF GLOBAL CGCS2000}

The Terrestrial Reference Frame (TRF) is generally constructed from two mathematical models (Altamimi, 2007). The one-step model combines the effective time series of different spatial technologies synchronously. The first step of the two-step model comprehensively processes the effective time series of different observation technique (Intra-technique combination). The second step is to achieve joint processing base on the first step to obtain effective parameter estimations (Inter-technique combination), generating the final ITRF results.

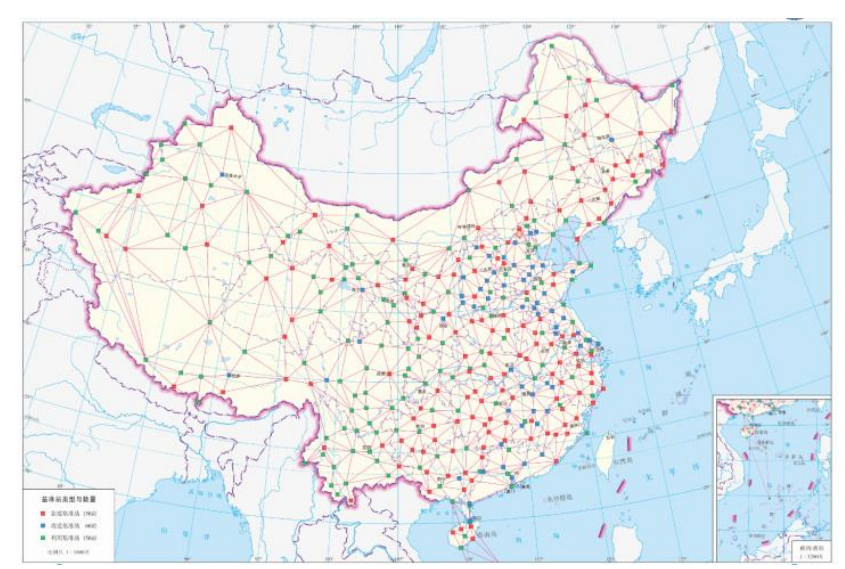

Figure 1. The map of national CORS stations 


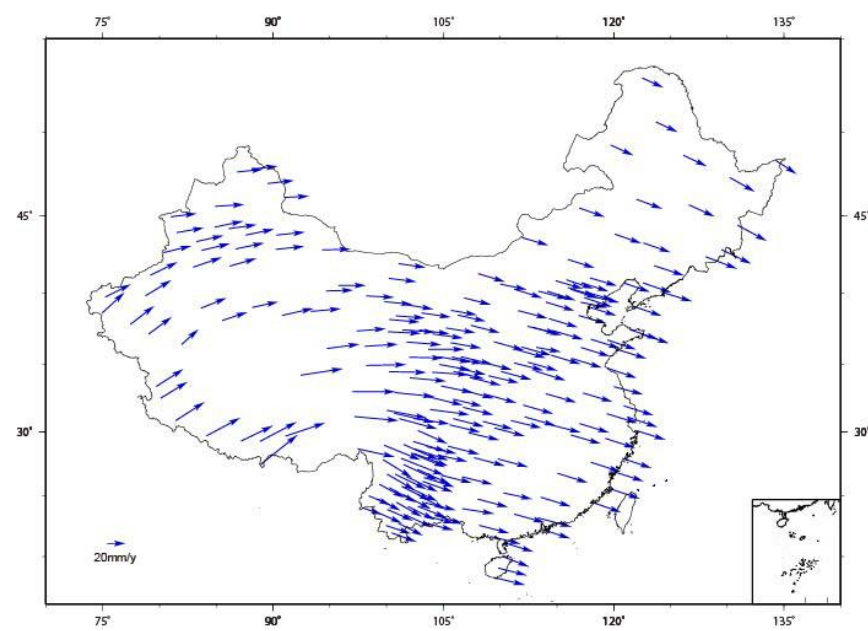

Figure 2. The velocity of national CORS stations (CGCS2000)

The advantage of the two-step model is estimating Terrestrial Reference Frame (TRF) parameters from different spatial technique; which reveals the systematic deviations among technique through comparison analysis. For example, scale deviations, accuracy differences, and observation gross errors. Secondly, the variance matrix of different spatial techniques obtained in the first step can be estimated and weighted appropriately. Otherwise, considering the characteristics of BDs at this stage, the two-step model is suitable. The following mainly introduces the two-step model.

\subsection{Intra-technique Combination Model}

Intra-technique combination model processes time series generated from different observation technology separately, assuming that different epochs of time series refer to different coordinate frames (epoch frames), the initial coordinates and velocity values of TRF had been estimated in the different coordinate time series. The nonlinear observation equations in the form below (Altamimi, 2011).

$$
\begin{aligned}
& \delta \tilde{x}_{i}^{k}=\delta \mathrm{x}_{i 0}+\left(t_{k}-t_{0}\right) \delta \mathrm{v}_{i}+s_{k} \mathrm{x}_{i 0}^{a p}+\left[\mathrm{x}_{i 0}^{a p} \times\right] \theta_{k}+d_{k}+e_{i}^{k} \\
& =\left[\begin{array}{ll}
I & \left(t_{k}-t_{0}\right)
\end{array}\right]\left[\begin{array}{c}
\delta \mathrm{x}_{i 0} \\
\delta \mathrm{v}_{i}
\end{array}\right]+\left[\begin{array}{lll}
{\left[\mathrm{x}_{i 0}^{a p} \times\right]} & I & \mathrm{x}_{i 0}^{a p}
\end{array}\right]\left[\begin{array}{c}
\theta_{k} \\
d_{k} \\
s_{k}
\end{array}\right]+e_{i}^{k}
\end{aligned}
$$

Where $\delta \mathrm{x}_{i 0}, \delta \mathrm{v}_{i}$ are respective corrections of approximate coordinates values and their constant velocities $V_{\mathrm{i} .} \theta_{k}, d_{k}, s_{k}$ are the transformation parameters from the technique $T$ reference system $S_{T}$ to the particular original data reference system $S_{k}$ at epoch $T_{k}$. This complication situation from the lack of individual station observe at some epochs, which can be handled by introducing a "participation" matrix $L_{\mathrm{k}}$. Finally, the total observation equations for the $\mathrm{M}$ epochs in the stacking of a particular technique below.

$$
\begin{gathered}
b=\delta x=\left[\begin{array}{c}
\delta x_{1} \\
\vdots \\
\delta x_{k} \\
\vdots \\
\delta x_{M}
\end{array}\right]=\left[\begin{array}{c}
L_{1} \\
\vdots \\
L_{k} \\
\vdots \\
L_{M}
\end{array}\right] x_{0}+\left[\begin{array}{c}
\left(t_{1}-t_{0}\right) L_{1} \\
\vdots \\
\left(t_{k}-t_{0}\right) L_{k} \\
\vdots \\
\left(t_{M}-t_{0}\right) L_{M}
\end{array}\right]\left[\begin{array}{ccccc}
L_{1} E & \cdots & 0 & \cdots & 0 \\
\vdots & \ddots & \vdots & \ddots & \vdots \\
0 & \cdots & L_{k} E & \cdots & 0 \\
\vdots & \ddots & \vdots & \ddots & \vdots \\
0 & \cdots & 0 & \cdots & L_{M} E
\end{array}\right]\left[\begin{array}{c}
z_{1} \\
\vdots \\
z_{k} \\
\vdots \\
z_{M}
\end{array}\right]+\left[\begin{array}{c}
e_{1} \\
\vdots \\
e_{k} \\
\vdots \\
e_{M}
\end{array}\right]= \\
=A_{x_{0}} x_{0}+A_{v} v+A_{z} z+e=\left[\begin{array}{lll}
A_{x_{0}} & A_{v} & A_{z}
\end{array}\right]\left[\begin{array}{c}
x_{0} \\
v \\
z
\end{array}\right]+e=A x+e= \\
{\left[\begin{array}{ll}
A_{x_{0}} & A_{v}
\end{array}\right]\left[\begin{array}{c}
x_{0} \\
v
\end{array}\right]+A_{z} z+e=A_{a} a+A_{z} z+e=\left[\begin{array}{ll}
A_{a} & A_{z}
\end{array}\right]\left[\begin{array}{l}
a \\
z
\end{array}\right]+e=A x+e} \\
A_{a}=\left[\begin{array}{cc}
A_{x_{0}} & A_{v}
\end{array}\right], \quad a=\left[\begin{array}{c}
x_{0} \\
v
\end{array}\right]
\end{gathered}
$$

With weight matrix

$$
P=\left[\begin{array}{ccccc}
P_{1} & \cdots & 0 & \cdots & 0 \\
\vdots & \ddots & \vdots & \ddots & \vdots \\
0 & \cdots & P_{k} & \cdots & 0 \\
\vdots & \ddots & \vdots & \ddots & \vdots \\
0 & \cdots & 0 & \cdots & P_{M}
\end{array}\right]
$$

The normal equations $N \hat{x}=u$ with $N=A^{T} P A, u=A^{T} P b$ have an infinite number of solutions since $\mathrm{N}$ is singular. A unique solution is obtained by introducing a reference system through additional minimal constraints.

$$
\begin{aligned}
& N=\left[\begin{array}{cc}
N_{a} & N_{a z} \\
N_{z a} & N_{z}
\end{array}\right]=\left[\begin{array}{ccc}
N_{x_{0}} & N_{x v v} & N_{x_{0} z} \\
N_{v x_{0}} & N_{v} & N_{v z} \\
N_{z x_{0}} & N_{z v} & N_{z}
\end{array}\right]=\left[\begin{array}{ccc}
\sum_{k=1}^{M} \bar{P}_{k} & \sum_{k=1}^{M}\left(t_{k}-t_{0}\right) \bar{P}_{k} & \left(\sum_{k=1}^{M} \bar{P}_{k}\right) E \\
& \sum_{k=1}^{M}\left(t_{k}-t_{0}\right)^{2} \bar{P}_{k} & \left(\sum_{k=1}^{M}\left(t_{k}-t_{0}\right) \bar{P}_{k}\right) E \\
s y m m & E^{\mathrm{T}}\left(\sum_{k=1}^{M} \bar{P}_{k}\right) E
\end{array}\right] \\
& u=\left[\begin{array}{l}
u_{a} \\
u_{z}
\end{array}\right]=\left[\begin{array}{c}
u_{x_{0}} \\
u_{v} \\
u_{z}
\end{array}\right]=\left[\begin{array}{c}
\sum_{k=1}^{M} u_{k} \\
\sum_{k=1}^{M}\left(t_{k}-t_{0}\right) u_{k} \\
E^{T} \sum_{k=1}^{M} u_{k}
\end{array}\right], u_{k}=L_{k}^{T} P_{k} \Delta x_{k}
\end{aligned}
$$

$\bar{P}_{k}=L_{k}^{T} P_{k} L_{k}$ is the inflated $\mathrm{N}^{*} \mathrm{~N}$ weight matrix, resulting from $P_{k}$ by adding zero elements to the rows and columns corresponding to stations that do not observe at epoch $t_{k}$. The normal equations $N \hat{x}=u$ have a singular matrix $\mathrm{N}$, with a rank deficiency arising from the fact that the reference system to which the unknown parameters refer has not been defined, the infinitely many solutions of the normal equations correspond to the infinitely choices of the reference system. A particular reference system is chosen with the use of an additional set of the minimal constraints, which provide unique parameter estimates.

\subsection{Inter-technique Combination}

In inter-technique combination step, the initial coordinates and velocities $\left(\delta \hat{x}_{i_{0}}\right)_{T \mid T},\left(\delta \hat{\mathrm{v}}_{i}\right)_{T \mid T}, i=1_{T}, 2_{T}, \cdots, n_{T}$, as well the estimates $\quad\left(\hat{z}_{k}\right)_{T \mid T}, k_{T}=1_{T}, 2_{T}, \cdots \mathrm{m}_{T} \quad$ the nuisance transformation parameters at observations epochs $t_{1_{T}}, \cdots, t_{k_{T}}, \cdots, t_{m_{T}}$ obtained in the previous stacking step for 
each technique T separately, they are used as "observations" in order to obtain common estimates $\delta \hat{\mathrm{x}}_{i 0}, \delta \hat{\mathrm{v}}_{i}$ of the corresponding TRF model parameters as well of the transformation parameters. The model for the relevant estimation take the specific form of the following observation equations

$$
\begin{aligned}
& \left(\delta \tilde{x}_{0 i}\right)_{T T T}=\delta \mathbf{x}_{0 i}+\left[\mathbf{x}_{0 i}^{\mathrm{ap}} \times\right] \theta_{0 T}+S_{0 T} \mathbf{x}_{0 i}^{\mathrm{ap}}+d_{0 T}+e_{\left(\delta \hat{x}_{0 i}\right) T T} \\
& =\delta \mathbf{x}_{0 i}+\left[\begin{array}{lll}
{\left[\mathbf{x}_{0 i}^{\mathrm{ap}} \times\right]} & I & \mathbf{x}_{0 i}^{\mathrm{ap}}
\end{array}\right]\left[\begin{array}{c}
\theta_{0 T} \\
d_{0 T} \\
S_{0 T}
\end{array}\right]+e_{\left(\delta \hat{x}_{0 i}\right) T T}=\delta \mathbf{x}_{0 i}+E_{i} p_{0 T}+e_{\left(\delta \delta_{0 i}\right) T T}, i=1_{T}, 2_{T}, n_{T} \\
& \left(\delta \tilde{v}_{i}\right)_{T \mid T}=\delta v_{i}+\left[\mathbf{x}_{0 i}^{\mathrm{ap}} \times\right] \dot{\theta}_{T}+\dot{S}_{T} \mathbf{x}_{0 i}^{\mathrm{ap}}+\dot{d}_{T}+e_{\left(\delta \hat{v}_{i}\right)_{T \mid T}} \\
& =\delta v_{i}+\left[\begin{array}{lll}
{\left[\mathbf{x}_{0 i}^{\mathrm{ap}} \times\right]} & I & \left.\mathbf{x}_{0 i}^{\mathrm{ap}}\right]
\end{array}\right]\left[\begin{array}{c}
\dot{\theta}_{T} \\
\dot{d}_{T} \\
\dot{S}_{T}
\end{array}\right]+e_{\left(\delta \hat{v}_{i}\right) T \mid T}=\delta v_{i}+E_{i} \dot{p}_{T}+e_{\left(\delta \hat{v}_{i}\right) T T}, \quad i=1_{T}, 2_{T}, n_{T}
\end{aligned}
$$

In order to estimate the translate parameters from the global CGCS2000 reference frame (A) to the observational epoch reference frame $\mathrm{C}$, it is necessary to use the relationship between the three frame transformation parameters. The Frame Relationship Diagram are represented in Figure 3, the obtained observation equation is:

$$
\left(\hat{Z}_{k}\right)_{T \mid T}=Z_{k, T}-P_{\mathrm{O} T}-\left(t_{k}-t_{\mathrm{O}}\right) \dot{P}_{T}+e_{\left(\hat{Z}_{k}\right)_{T \mid T}}
$$

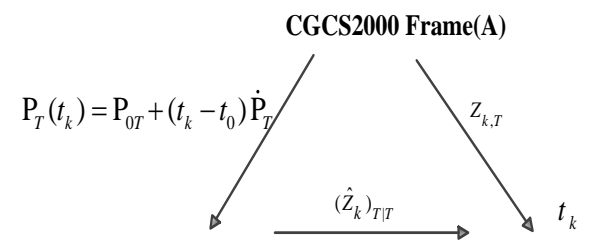

Technique Frame(B) Epochs Frame(C)

$$
\left(\hat{Z}_{k}\right)_{T \mid T}=Z_{k, T}-P_{0 T}-\left(t_{k}-t_{0}\right) \dot{P}_{T}+e_{\left(\hat{Z}_{k}\right)_{T \mid T}}
$$

Figure 3. Frame Relationship Diagram

Different technique networks participate in different technique $T=V, S, G, D, C$ ( VLBI , SLR , GPS , DORIS , COMPASS/Beidou, respectively ). The "observations" are the estimate $\left(\delta \hat{x}_{0 i}\right)_{T \mid T},\left(\delta \hat{v}_{i}\right)_{T \mid T}$ of station $i$ initial coordinates and constant velocities as well as the transformation parameters $\left(\hat{Z}_{k}\right)_{T \mid T}$, obtained in the technique stackings separately, which refer to different reference systems for each technique, introduced by independent minimal constraints in the separate stacking adjustments. The "unknowns" are the corresponding quantities $\delta x_{0 i}, \delta v_{i}$ for the stations of the total network, which is the union of the whole networks of each technique and the transformation parameters and $Z_{k, T}$ from CGCS2000 reference system to the individual reference systems of each observation epoch $t_{k}$ within all techniques $T$.

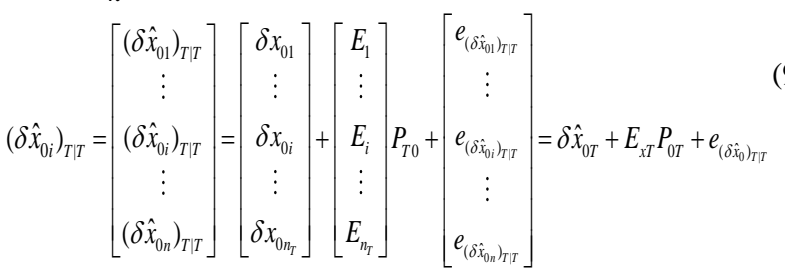

$$
\begin{aligned}
& (\delta \hat{v})_{T \mid T}=\left[\begin{array}{c}
\left(\delta v_{1}\right)_{T \mid T} \\
\vdots \\
\left(\delta v_{i}\right)_{T \mid T} \\
\vdots \\
\left(\delta v_{n}\right)_{T \mid T}
\end{array}\right]=\left[\begin{array}{c}
\delta v_{1} \\
\vdots \\
\delta v_{i} \\
\vdots \\
\delta v_{n_{T}}
\end{array}\right]+\left[\begin{array}{c}
E_{1} \\
\vdots \\
E_{i} \\
\vdots \\
E_{n_{T}}
\end{array}\right] \dot{P}_{T}+\left[\begin{array}{c}
e_{\left(\delta \hat{v}_{1}\right)_{T \mid T}} \\
\vdots \\
e_{\left(\delta \hat{v}_{i}\right)_{T \mid T}} \\
\vdots \\
e_{\left(\delta \hat{v}_{n}\right)_{T \mid T}}
\end{array}\right]=\delta v_{T}+E_{x T} \dot{P}_{T}+e_{(\delta \hat{v})_{T \mid T}}(10) \\
& \hat{z}_{T \mid T}=\left[\begin{array}{c}
(\hat{z})_{T \mid T} \\
\vdots \\
\left(\hat{z}_{k}\right)_{T \mid T} \\
\vdots \\
\left(\hat{z}_{m}\right)_{T \mid T}
\end{array}\right]=\left[\begin{array}{c}
z_{1, T} \\
\vdots \\
z_{k, t} \\
\vdots \\
z_{m, t}
\end{array}\right]-\left[\begin{array}{cc}
I & \left(t_{1}-t_{0}\right) I \\
\vdots & \vdots \\
I & \left(t_{k}-t_{0}\right) I \\
\vdots & \vdots \\
I & \left(t_{m}-t_{0}\right) I
\end{array}\right]\left[\begin{array}{c}
e_{\left(\hat{u}_{1}\right)_{T \mid T}} \\
\vdots \\
p_{0 s} \\
\dot{p}_{s}
\end{array}\right]+\left[\begin{array}{c}
e_{\left(\hat{z}_{k}\right)_{T T T}} \\
\vdots \\
e_{\left(\hat{z}_{m}\right)_{T T T}}
\end{array}\right]=z_{T}+E_{z T} P_{T}+e_{\hat{z}_{T \mid T}} \\
& \text { 3.3 The Inner Constraints for the Inter-technique } \\
& \text { Combination }
\end{aligned}
$$

Inner constraints algorithm redefine constraint conditions of coordinate reference frame according to minimum standard of transform parameters and its rate, adjusted network which is obtained though Coordinate similarity transformation can ensure the highest fitting degree to the initial network shape, and can keep the inherent purity of coordinate network from different observation technology (Wei, 2010). Due to the limited space of the paper, we omit the inner constraints for the Intra-technique stacking step. Brief introduction the inner constraints for the Inter-technique combination, the transformation law is

$\left[\begin{array}{l}\tilde{\boldsymbol{a}} \\ \tilde{\mathbf{z}}\end{array}\right]=\left[\begin{array}{l}\boldsymbol{a} \\ \boldsymbol{z}\end{array}\right]+\left[\begin{array}{l}\boldsymbol{E}_{a} \\ \boldsymbol{E}_{z}\end{array}\right] \boldsymbol{p}=\left[\begin{array}{l}\boldsymbol{a} \\ \mathrm{z}\end{array}\right]+\boldsymbol{E}_{\boldsymbol{p}}{ }^{(12)}$

And the inner constraints become

$$
\begin{aligned}
& 0=E^{T}\left[\begin{array}{l}
a \\
\mathrm{z}
\end{array}\right]=\left[\begin{array}{ll}
E_{a}^{T} & E_{z}^{T}
\end{array}\right]\left[\begin{array}{l}
a \\
\mathrm{z}
\end{array}\right]=E_{a}^{T} a+E_{z}^{T} \mathrm{z} \\
& =\sum_{i=1}^{N} E_{a_{i}}^{T} a_{i}+\sum_{i=1}^{M} E_{z_{T}}^{T} z_{T}=\left[\begin{array}{c}
-\sum_{i=1}^{N}\left[\mathbf{x}_{0 i}^{\mathrm{ap}} \times\right] \delta \mathbf{x}_{0 i}-\sum_{k=1}^{M} \mathbf{\theta}_{T_{0}} \\
\sum_{i=1}^{N} \delta \mathbf{x}_{0 i}-\sum_{k=1}^{M} \mathbf{d}_{T_{0}} \\
\sum_{i=1}^{N}\left(\mathbf{x}_{0 i}^{\mathrm{ap}}\right)^{T} \delta \mathbf{x}_{0 i}-\sum_{k=1}^{M} s_{T_{0}} \\
-\sum_{i=1}^{N}\left[\mathbf{x}_{0 i}^{\mathrm{ap}} \times\right] \delta \mathbf{v}_{i}-\sum_{k=1}^{M}\left(t_{k}-t_{0}\right) \boldsymbol{\theta}_{T} \\
\sum_{i=1}^{N} \delta \mathbf{v}_{i}-\sum_{k=1}^{M}\left(t_{k}-t_{0}\right) d_{T} \\
\sum_{i=1}^{N}\left(\mathbf{x}_{0 i}^{\mathrm{ap}}\right)^{T} \delta \mathbf{v}_{i}-\sum_{k=1}^{M}\left(t_{k}-t_{0}\right) s_{T}
\end{array}\right]=\mathbf{0}
\end{aligned}
$$

These are the "total" inner constraints leading to a minimum norm solution satisfying.

$\left\|\left[\begin{array}{l}x \\ z\end{array}\right]\right\|^{2}=\left[\begin{array}{l}x \\ z\end{array}\right]^{T}\left[\begin{array}{l}x \\ z\end{array}\right]=x^{T} x+z^{T} z$

$=\sum\left(\delta \mathrm{x}_{i 0}^{T} \delta \mathrm{x}_{i 0}+\delta v_{i}^{T} \delta v_{i}\right)+\sum_{T}\left(\mathbf{\theta}_{T 0}^{T} \boldsymbol{\theta}_{T 0}+\mathbf{d}_{T 0}^{T} \mathbf{d}_{T 0}+s_{T 0}^{2}+\dot{\boldsymbol{\theta}}_{T}^{T} \dot{\boldsymbol{\theta}}_{T}+\dot{\mathbf{d}}_{T}^{T} \dot{\mathbf{d}}_{T}+\dot{s}_{T}^{2}\right)=\min$

\section{NOISE ESTIMATION OF NATIONAL CORS}

The noise characteristic of the national CORS coordinate time series are estimated quantitatively with the criterion of maximum likelihood estimation(Williams,2006), Table 1 lists the power spectrum index estimates and the white noise and colored noise parameter estimates for the north, east and high components of the national CORS station coordinate time series. From the spectral index estimates listed in Table 1, the power component of the horizontal component of the CORS station is 
The International Archives of the Photogrammetry, Remote Sensing and Spatial Information Sciences, Volume XLII-3, 2018 ISPRS TC III Mid-term Symposium "Developments, Technologies and Applications in Remote Sensing", 7-10 May, Beijing, China

mostly between -1.0 and -0.0 , while the index of a few stations is less than -1.0. Most of the indices are less than -1.0 , and a few of the station spectrum indices are between -1.0 and -0.0 . The statistical results not only demonstrate that the CORS station noise does not meet the pure white noise nature, white noise is not the main component of, and the nature of the national CORS station is closer to the superposition of white noise, flicker noise and random walk noise. Results of spectral index and estimated parameters are represented in Table 1.

\begin{tabular}{|c|c|c|c|c|c|}
\hline Name & Component & Spectral Index & $\begin{array}{c}\text { VW } \\
\text { Value }\end{array}$ & FN Value & $\begin{array}{c}\text { RW } \\
\text { Value }\end{array}$ \\
\hline \multirow[t]{3}{*}{ BJFS } & $\mathrm{N}$ & -0.94 & 1.13 & 6.76 & \\
\hline & $\mathrm{E}$ & -0.75 & 1 & 7.08 & \\
\hline & $\mathrm{U}$ & -1.13 & 1.52 & 26.59 & 8.75 \\
\hline \multirow[t]{3}{*}{ BJSH } & $\mathrm{N}$ & -0.81 & 1.02 & 6.74 & \\
\hline & $\mathrm{E}$ & -0.83 & 1.01 & 7.27 & \\
\hline & $\mathrm{U}$ & -1.16 & 1.2 & 21.58 & 6.11 \\
\hline \multirow[t]{3}{*}{ CHUN } & $\mathrm{N}$ & -0.94 & 0.95 & 7.72 & \\
\hline & $\mathrm{E}$ & -0.66 & 1.08 & 8.89 & \\
\hline & $\mathrm{U}$ & -0.88 & 0.83 & 24.62 & \\
\hline \multirow[t]{3}{*}{ DLHA } & $\mathrm{N}$ & -1.41 & 0.96 & 3.28 & 6.69 \\
\hline & E & -0.97 & 0.92 & 8.82 & \\
\hline & $\mathrm{U}$ & -1.09 & 1.1 & 24.44 & \\
\hline \multirow[t]{3}{*}{ DXIN } & $\mathrm{N}$ & -1.07 & 0.88 & 6.24 & \\
\hline & E & -1.05 & 0.82 & 8.51 & \\
\hline & $\mathrm{U}$ & -1.17 & 1.09 & 24.71 & 7.92 \\
\hline \multirow[t]{3}{*}{ GUAN } & $\mathrm{N}$ & -0.94 & 1.12 & 8.08 & \\
\hline & $\mathrm{E}$ & -0.82 & 0.83 & 14.13 & \\
\hline & $\mathrm{U}$ & -1.47 & 1 & 32.39 & 24.98 \\
\hline \multirow[t]{3}{*}{ HAIK } & $\mathrm{N}$ & -1.11 & 1.29 & 10.07 & \\
\hline & $\mathrm{E}$ & -0.91 & 1.06 & 16.65 & \\
\hline & $\mathrm{U}$ & -0.97 & 1.04 & 38.38 & \\
\hline \multirow[t]{3}{*}{ HLAR } & $\mathrm{N}$ & -1.12 & 0.93 & 8.18 & \\
\hline & $\mathrm{E}$ & -0.58 & 1 & 9.18 & \\
\hline & $\mathrm{U}$ & -1.35 & 1.22 & 23.38 & 13.24 \\
\hline \multirow[t]{3}{*}{ HRBN } & $\mathrm{N}$ & -1.13 & 1.07 & 8.34 & \\
\hline & E & -0.89 & 1.06 & 9.2 & \\
\hline & $\mathrm{U}$ & -1.12 & 1.22 & 29.65 & \\
\hline \multirow[t]{3}{*}{ JIXN } & $\mathrm{N}$ & -0.83 & 1.04 & 7.6 & \\
\hline & $\mathrm{E}$ & -0.78 & 1.02 & 8.15 & \\
\hline & $\mathrm{U}$ & -1.01 & 1 & 20.74 & \\
\hline \multirow[t]{3}{*}{ KMIN } & $\mathrm{N}$ & -0.83 & 0.96 & 7.72 & \\
\hline & $\mathrm{E}$ & -0.83 & 1 & 16.31 & \\
\hline & $\mathrm{U}$ & -1.13 & 0.87 & 45.29 & \\
\hline LHAS & $\mathrm{N}$ & -1.52 & 1.08 & 36.32 & \\
\hline
\end{tabular}

\begin{tabular}{|c|c|c|c|c|c|}
\hline Name & Component & Spectral Index & $\begin{array}{c}\text { VW } \\
\text { Value }\end{array}$ & FN Value & $\begin{array}{c}\text { RW } \\
\text { Value }\end{array}$ \\
\hline & E & -0.42 & 0.93 & 11.82 & \\
\hline & $\mathrm{U}$ & -0.97 & 1.1 & 27.92 & 5.01 \\
\hline \multirow[t]{3}{*}{ LUZH } & $\mathrm{N}$ & -1.21 & 1.24 & 8.11 & \\
\hline & E & -1.36 & 1.56 & 10.5 & 6.54 \\
\hline & $\mathrm{U}$ & -1.21 & 1.08 & 24.08 & 8.27 \\
\hline \multirow[t]{3}{*}{ QION } & $\mathrm{N}$ & -0.93 & 1.22 & 10.52 & \\
\hline & E & -1.02 & 1.1 & 17.81 & \\
\hline & $\mathrm{U}$ & -1.03 & 0.97 & 37.24 & \\
\hline \multirow[t]{3}{*}{ SHAO } & $\mathrm{N}$ & -1.04 & 1.44 & 10.69 & \\
\hline & E & -0.92 & 1.14 & 12.81 & \\
\hline & $\mathrm{U}$ & -0.61 & 0.99 & 24.37 & \\
\hline \multirow[t]{3}{*}{ SUIY } & $\mathrm{N}$ & -0.7 & 0.94 & 8.11 & \\
\hline & E & -0.94 & 0.96 & 10.01 & \\
\hline & $\mathrm{U}$ & -1.49 & 1.01 & 19.54 & 27.61 \\
\hline \multirow[t]{3}{*}{ TAIN } & $\mathrm{N}$ & -0.55 & 1.12 & 6.86 & \\
\hline & E & -0.94 & 1.01 & 8.3 & \\
\hline & $\mathrm{U}$ & -1.12 & 1.02 & 22.56 & 5.47 \\
\hline \multirow[t]{3}{*}{ TASH } & $\mathrm{N}$ & -1.41 & 0.98 & 5.21 & 7.23 \\
\hline & E & -0.98 & 0.86 & 12.72 & \\
\hline & $\mathrm{U}$ & -1.14 & 1.08 & 28.3 & 9.07 \\
\hline \multirow[t]{3}{*}{ URUM } & $\mathrm{N}$ & -1.68 & 2.04 & 4.52 & 16.26 \\
\hline & $\mathrm{E}$ & -1.07 & 1.75 & 5.64 & \\
\hline & $\mathrm{U}$ & -1.48 & 1.82 & 29.91 & 29.5 \\
\hline \multirow[t]{3}{*}{ WUHN } & $\mathrm{N}$ & -0.42 & 1.14 & 8.2 & \\
\hline & E & -0.97 & 1.19 & 11.29 & 2.59 \\
\hline & $\mathrm{U}$ & -0.73 & 1.02 & 29.78 & \\
\hline \multirow[t]{3}{*}{ WUSH } & $\mathrm{N}$ & -1.32 & 1.06 & 5.29 & 5.63 \\
\hline & $\mathrm{E}$ & -0.95 & 0.93 & 11.04 & \\
\hline & $\mathrm{U}$ & -1.23 & 1.36 & 28.25 & 10.95 \\
\hline \multirow[t]{3}{*}{ XANY } & $\mathrm{N}$ & -1.15 & 1.13 & 6.39 & \\
\hline & E & -1 & 1 & 8.54 & \\
\hline & $\mathrm{U}$ & -0.88 & 0.98 & 23.28 & \\
\hline \multirow[t]{3}{*}{ XIAA } & $\mathrm{N}$ & -1.3 & 1.27 & 6.41 & 3.06 \\
\hline & E & -1.19 & 1.15 & 8.13 & 3.18 \\
\hline & $\mathrm{U}$ & -1.28 & 1.25 & 22.18 & 9.91 \\
\hline \multirow[t]{3}{*}{ XIAG } & $\mathrm{N}$ & -0.94 & 1.39 & 9.41 & \\
\hline & $\mathrm{E}$ & -0.71 & 1.33 & 15.91 & \\
\hline & $\mathrm{U}$ & -1.14 & 1.34 & 37.92 & 7.93 \\
\hline \multirow[t]{2}{*}{ XIAM } & $\mathrm{N}$ & -0.34 & 1.09 & 6.36 & \\
\hline & E & -1.11 & 1.07 & 13.12 & \\
\hline
\end{tabular}




\begin{tabular}{cccccc}
\hline \multirow{2}{*}{ Name } & Component & Spectral Index & $\begin{array}{c}\text { VW } \\
\text { Value }\end{array}$ & FN Value & $\begin{array}{c}\text { RW } \\
\text { Value }\end{array}$ \\
\hline \multirow{2}{*}{ XNIN } & U & -0.84 & 0.86 & 31.66 & \\
& N & -1.31 & 1.05 & 4.48 & 5.45 \\
& E & 7.89 & 0.88 & 8.33 & \\
YANC & U & -1.19 & 1.24 & 22.98 & 7.57 \\
& N & -1.17 & 1.06 & 6.31 & 2.02 \\
& E & -0.67 & 0.83 & 8.33 & \\
YONG & U & -1.45 & 1.57 & 23.76 & 16.71 \\
& N & -1.2 & 1.07 & 6.97 & 3.13 \\
& E & -0.74 & 0.73 & 15.57 & \\
& U & -0.87 & 0.62 & 38.73 & \\
& U & -0.84 & 0.86 & 31.66 & \\
\hline
\end{tabular}

Table 1. Results of spectral index and estimated parameters of noise property based on $\mathrm{FN}+\mathrm{VW}+\mathrm{RW}$ model (unit: $\mathrm{mm}$ )

VW corresponds to the variable white noise, FN corresponds to FLICKER noise; RW corresponds to stochastical noise.

\section{CONCLUSION}

We can obtain the conclusion based on above analysis:

1. Finely processed coordinates and velocities of Chinese mainland have been obtained derived from recent 15 years continuous observation results of state CORS network and the GNSS stations, which is the most precise (coordination better than $5 \mathrm{~mm}$, velocity better than $2 \mathrm{~mm} / \mathrm{a}$ ), Wide area (covering Chinese mainland), and densest (1081 points).

2. This paper studies the construction mathematical model of the Global CGCS2000 Frame, analyzes the theory and algorithm of inner constraints required for of Global CGCS2000 Frame formulation. Inner constraints algorithm redefine constraint conditions of coordinate reference frame according to minimum standard of transform parameters and its rate. Through Coordinate similarity transformation, adjusted network which ensures the highest fitting to the initial network shape, and can keep the inherent purity of coordinate network from different observation technology.

3. The noise characteristic of the coordinate time series are estimated quantitatively with the criterion of maximum likelihood estimation. Result proves that white noise is not the main part of the noises in the coordinate time series of CORS network in China, while the white noise, flicker noise and random walk noise are the basic characteristics in the coordinate time series of CORS network, better describing the movement parameters of CORS network.

\section{REFERENCES}

Yang Yuanxi, 2009. Chinese Geodetic Coordinate System 2000[J]. Chinese Science Bulletin, 54(15), pp. 2271-2276.

Liu Jingnan, LiuHui, Zou Rong, et al., 2009. Some Thoughts on the Establishment of Nationwide Continuously Operating
Reference Stations [J]. Geomatics and Information Science of Wuhan University, 34(11), pp. 1261-1265.

Jiang Zhihao,Zhang Peng and Bei Jinzhong, etc., 2009.The Model of Crustal Horizontal Movement Based on CGCS2000 Frame[J]. (6), pp. 471-476.

Jiang Zhihao, Zhang Peng, 2012. Characteristics of the nonlinear movement of CORS network in China based on the CGCS2000 frame, CHINESE JOURNAL OF GEOPHYSICS [J], 55 (3), pp. 841-850.

Altamimi Z., P. Sillard, C. Boucher, 2002. ITRF2000: A New Release of the International Terrestrial Reference Frame for Earth Science Applications [J], Journal of Geophysical Research, 107 (B10), pp. 2214.

Z Altamimi,X Collilieux,J Legrand,B Garayt,C, 2007. Boucher.ITRF2005: a new release of the international terrestrial reference frame based on time series of station positions and Earth orientation parameters [J]. Journal of Geophysical Research.

Z Altamimi,X Collilieux,et al., 2011. ITRF2008: an improved solution of the international terrestrial reference frame [J]. $J$ of Geod., DOI 10.1007/s00190-011-0444-4.

Jiang Zhihao, Zhang Peng, Bi Jinzhong,Liu Lifen,2010. Velocity Estimation on the Colored Noise Properties of CORS Network in China Base on the CGCS2000 Frame. Acta Geodaetica et Cartographica Sinica (in Chinese)[J],39(4), pp. 355-363.

Zhou Rong, 2009. The Researchof Key Technology on the Realization and Maintainance of TRF [D], School of Geodesy and Geomatics, Wuhan University.

Zhang XiGuang, 2009. Theory and Algorithms of Terrestrial Reference Frame [D], PLA Information Engineering University.

Wei Na,Shi Chuang,Geng ChangJiang,Liu JingNan, 2010. Helmert Transformation of Reference Frame, JOURNAL OF GEODESY AND GEODYNAMICS[J], 30(4), pp. 109-112.

Zuheir Altamimi, Athanasios Dermanis, 2009. Theoretical foundations of ITRF determination. The algebraic and the kinematic approach[C], Presented at the VII Hotine-Marussi Symposium, Rome, July 6-10.

Z Altamimi,X Collilieux, 2009. IGS contribution to the ITRF [J]. J of Geod, 83(3-4):375-383. doi:10.1007 /s00190-008-0294.

Williams S D P, Willis P., 2006. Error analysis of weekly station coordinates in the DORIS network. J . Geodes y, 80 (811), pp. 525-539.

Sillard P, Boucher C, 2001. A review of algebraic constraints in terrestrial reference frame datum definition [J]. J Geod 75:6373

Dermanis, A., 2011. On the alternative approaches to IITRF formulation. A theoretical comparison. Proceeding IUGG General Assembly, Melbourne. 
The International Archives of the Photogrammetry, Remote Sensing and Spatial Information Sciences, Volume XLII-3, 2018 ISPRS TC III Mid-term Symposium "Developments, Technologies and Applications in Remote Sensing", 7-10 May, Beijing, China

Williams S D P, Yehuda Bock, Peng Fang, et al., 2004. Error analysis of continuous GPS position time series. J. Geophys. Res. B03412, doi:10.1029/2003JB002741.

Williams S D P, 2003. The effect of coloured noise on the uncertainties of rates estimated from geodetic time series Journal of Geodesy, 76, pp. 483 - 494, DOI 10.1007/s00190002-0283-4.

Dong D, Fang P, Bock Y, et al., 2006. Spatiotemporal filtering using principal component analysis and Karhunen-Loeve expansion approaches for regional GPS network analysis. J .Geophys. Res.-Sol. Ea., 111 (B3), B03405, doi :10.1029/ 2005JB003806 